\title{
Research on the Effectiveness of Physical Education Classroom Teaching and Diagnosis and Optimization
}

\author{
Niu Meihui \\ Southwest Petroleum University Nanchong Campus, Sichuan, China, 637000
}

Keywords: physical education classroom teaching, effectiveness, reform and innovation, diagnostic optimization

Abstract: Teaching content is the core of classroom teaching. Physical education teachers generally choose appropriate teaching methods and teaching organization forms according to the characteristics of teaching content. The physical education materials of the new curriculum did not give the physical education teachers the specific teaching content of each class, and provided a broad stage for the majority of physical education teachers. How to choose and match teaching content reasonably and effectively is the fundamental guarantee for improving the effectiveness of classroom teaching. The experimental teaching reform is able to get responses from students in the physical education discipline. It is a feasible experimental teaching reform idea to open an innovative comprehensive experimental course in college physical education.

\section{Introduction}

Today, with the development of sports science research and continuous improvement, the concept of sports is no longer the traditional body movement and blind hard training, but through the scientific research and analysis of human life mechanism, as well as various modern testing and monitoring methods. Seek more scientific and rational physical exercise methods to further tap the potential of human sports. The teaching goal is the guide and basis for the whole teaching activities of the physical education curriculum. The more specific and precise the teaching objectives are, the more operable. The goal can't be set too high, the students are hopeful and fearful, and the courage to lose the challenge; nor can it be set too low and can be achieved without hard work, so that the enthusiasm of the students cannot be mobilized. Generally speaking, students should be able to get the best by "jumping" through hard work.

\section{The status quo of experimental teaching in college physical education}

\subsection{The experimental project is repeated, the content is old, and the form is rigid.}

For many years, the introduction of experimental teaching courses in various disciplines of physical education has been the traditional basic theory courses, such as exercise physiology, sports biochemistry, biomechanics, sports health and anthropometry and evaluation. The professional 
course experiments are basically blank. The content of the experimental course now is based on a confirmatory basic experiment, which has not been updated for many years ${ }^{[1]}$.

Table 1 Student Physical Exercise Frequency Table (N=579)

\begin{tabular}{cccccccc}
\hline $\begin{array}{c}\text { Movement frequency } \\
\text { (times/week) }\end{array}$ & 0 & 1 & 2 & 3 & $>3$ & X2 & P \\
\hline Number of people & 24 & 298 & 128 & 102 & 27 & 184.796 & 0.000 \\
Percentage (\%) & 4.1 & 51.4 & 22.1 & 17.6 & 4.6 & & \\
\hline
\end{tabular}

Through the random sampling of 579 students from our school to conduct extracurricular physical exercise time and frequency survey, we can get an overall understanding of the development of our school's sports experiment project (the results are shown in Table 1 and Table 2). Obviously, under the existing fixed experimental teaching mode based on teacher's explanation, it is difficult for students to have more exercise in the experimental class in terms of hands-on ability, operational skills and ability to analyze and solve practical problems. And improve ${ }^{[2]}$.

Table 2 Extracurricular physical exercise time/time of our students $(\mathrm{N}=579)$

\begin{tabular}{cccccc}
\hline Exercise time $(\mathrm{min})$ & $<30$ & $30-60$ & $>60$ & $\mathrm{X} 2$ & $\mathrm{P}$ \\
\hline Number of people & 319 & 169 & 91 & 232.624 & 0.000 \\
Percentage $(\%)$ & 55.1 & 29.2 & 15.7 & & \\
\hline
\end{tabular}

\subsection{The experimental teaching system is backward, which is not conducive to the teaching and learning enthusiasm}

Under the framework of the experimental class attached to the theoretical class, the experimental courses currently held are arranged in the total class time of the theoretical class. Due to the total class time, the amount of experimental class is obviously insufficient. Moreover, an experiment usually needs to be divided into two or three small classes ${ }^{[1]}$. The workload of the experimental class is far greater than that of the teacher. Therefore, for teachers, taking the experimental class increases their workload, but such cases it is often not reflected in the distribution. Therefore, teachers should not be too high in terms of increasing the experimental class, adding experimental content, and reforming the experimental teaching mode. Without the support and encouragement of the policy, the experimental teaching can only follow the original model.

\subsection{Design, innovative experiment lacks policy orientation}

The sports policy has become relatively lagging behind the policy measures for experimental teaching reform. This is related to the long-standing understanding of the inertia of sports disciplines. It is believed that the level of physical education is mainly reflected in the level of students' sports skills and is reflected in various competition achievements. In the postgraduate recommendation system and various incentive measures with incentive effect, it is mainly based on the students' theoretical course scores. As for whether students have a solid experimental learning foundation and the potential of innovative research, it is impossible to demonstrate and cannot be verified. Because of the lack of incentives for experimental skills learning, the experimental teaching pattern of physical education has not changed significantly, and the awareness of carrying out comprehensive design and innovative experiments is not enough, leading to the long-term backwardness and obsolescence of experimental teaching in physical education ${ }^{[3]}$. 


\section{Reform attempts and effects analysis}

In order to promote the reform work in the field of experimental teaching of physical education, some college laboratories have gradually opened up some inter-disciplinary comprehensive experiments in the third-grade students of sports human science and physical education. According to the characteristics of the comprehensive experiment of the physical education discipline, students are encouraged to carry out experiments with the experimental group as the unit and carry out comprehensive experimental design. After the formation of the experimental group, we designed the experimental plan according to the experimental topics, clarified the experimental division of labor, consulted the relevant materials separately, and focused on the experimental process responsible for it, and jointly formulated specific experimental plans and steps on this basis. The instructor will give some guidance on the design of the program in this process, and give key guidance on the specific experimental operation skills. And use the card square test formula to analyze the results of the reform attempt:

$$
\chi^{2}=\sum \frac{\left(f_{0}-f_{e}\right)^{2}}{f_{e}} \sim \chi^{2}
$$

This is the original formula for the chi-square test, where the larger $f_{e}\left(f_{e} \geq 5\right)$, the better the approximation. Obviously, the greater the difference between $f_{o}$ and $f_{e}$, the larger the chi-square value; the smaller the difference between $f_{o}$ and $f_{e}$, the smaller the chi-square value; therefore, it can be used to indicate the degree of difference between $f_{o}$ and $f_{e}$. According to this formula, it can be seen from Tables 1 and 2 above that the training time of each student in our school group is less than 30 minutes, accounting for $55.1 \%$, and the card square test for different exercise time before the author investigates. , X2 $=232.624$, the significant probability of zero is significant difference, so it is obvious that the number of people who exercise less than 30 minutes is the most, which also shows that the overall training time of high school students in RI Zhao City is less ${ }^{[2]}$.

\section{Ideas for the Reform of Experimental Teaching of Physical Education in Colleges and Universities}

\subsection{Update the experimental teaching content and establish a new experimental teaching system}

Faced with the endless reality of new theories, new research methods and means in the field of sports science, college experimental teaching should actively follow this change in the concept, software and hardware environment and reform measures, and actively adapt to the progress of sports science and various types. The demand for sports talents in sports jobs should not be self-styled. The original experimental teaching mode and rhythm are still maintained, and no changes are made. At present, efforts should be made to improve the experimental teaching conditions. On the basis of increasing the investment in experimental equipment, it is necessary to re-integrate the existing experimental teaching courses in the physical education discipline.

\subsection{Combine different professional needs and increase professional experiment}

The setting of college physical education experimental teaching courses has always been based on basic course experiments, and it emphasizes theoretical verification. The professional experiments that are more closely related to the development of professional sports practice and professional competence are almost blank, such as dynamic measurement and mechanical analysis of various sports technical movements, design and monitoring of athlete physical training, 
simulation of modern competition layout, modern timing, Scores, ranging techniques, etc., can only be theoretically described and introduced by teachers in related courses in different majors, and there is no relevant experimental teaching content ${ }^{[3]}$.
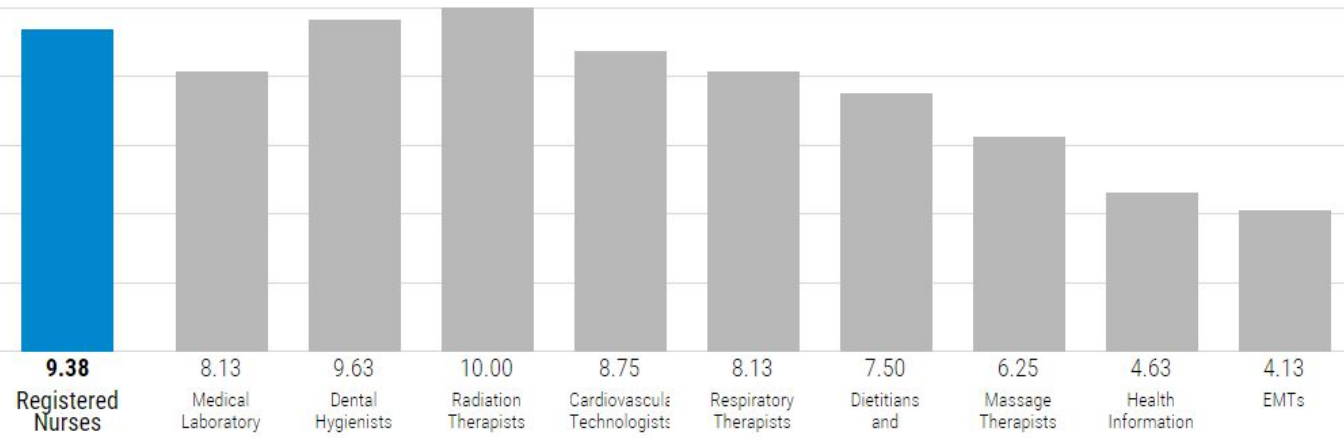

Figure 1 The development trend of the effectiveness of physical education classroom teaching

\subsection{Experimental classes are taught separately}

In order to further reflect the importance of experimental teaching in the process of talent training in colleges and universities, and to maximize the enthusiasm and initiative of teachers and students in experimental teaching, students can be enrolled in the third and fourth grades of students to obtain credits. "Comprehensive Experimental Class." The main purpose of this course is to encourage students to actively participate in the practice of innovative and comprehensive experiments through policy guidance. Students can choose experimental topics in the laboratory or the topics designated by the instructor, or they can self-report the questions. As long as they are jointly demonstrated by the laboratory and the instructor group, it is feasible to agree that the topic has certain practical significance and experimental value.

\subsection{Implementation of the laboratory opens system}

Students should be encouraged to actively participate in experimental exploration activities, improve their practical operation and overall comprehensive ability in the course of experiments, and make the concept of establishing a "comprehensive experiment course" operable. It is necessary to truly implement the open laboratory system and improve the laboratory opening. A series of management procedures, staffing, funding sources, etc., and cannot just stay on the verbal. Because only laboratory openness becomes a normal state, a system can ensure that students can arrange their own time for experimental activities, ensure the guidance and management of students during the experimental process, and ensure the smooth flow of experimental funding channels.

\section{Conclusions}

Experimental teaching is a very important part of physical education in colleges and universities. It plays an irreplaceable role in cultivating students' practical ability, analyzing problem-solving ability, scientific and rigorous thinking, and is also an effective way to cultivate students' innovative ability. Therefore, how to reform the experimental teaching mode of physical education and make it more conducive to the improvement of students' comprehensive quality and ability is worthy of long-term attention for experimental workers and related educators. 


\section{References}

[1] Yan X D. Research on the Effectiveness of College Physical Education Teaching Based on Network Media [J]. Education Teaching Forum, 2017.

[2] Chen C. Study on the Effectiveness of Applying Flipped Classroom Mode to College English Teaching of Art and Physical Education Students [J]. Journal of Hubei Correspondence University, 2017.

[3] Jin H Z. Research on the Effectiveness and Improving Strategies of PE Teaching under the Informatization Environment [J]. Journal of Hebei Institute of Physical Education, 2016. 